\title{
A 780-year annually resolved record of Indian Ocean monsoon precipitation from a speleothem from south Oman
}

\author{
Stephen J. Burns, ${ }^{1}$ Dominik Fleitmann, ${ }^{2}$ Manfred Mudelsee, ${ }^{3}$ Ulrich Neff, ${ }^{4}$ Albert Matter, ${ }^{2}$ \\ and Augusto Mangini ${ }^{4}$
}

Received 7 September 2001; revised 1 February 2002; accepted 5 February 2002; published 25 October 2002.

[1] Meteorological records of monsoon rainfall in the Indian Ocean are generally less than 100 years long. The relative brevity of these records makes it difficult to investigate monsoon variation on decadal and centennial timescales, to determine what factors influence the intensity of rainfall on these timescales, or to place possible changes in the twentieth century into a broader historical context. Development of a geologic proxy for rainfall that records annual variation in the monsoon over much longer time periods than are covered by instrumental records would be a significant step forward. We have developed an annually resolved record of monsoon rainfall variation for the past 780 years based on annual layer thickness and stable isotope analyses of a laminated stalagmite from southern Arabia. Our results show that monsoon variation over the past century is not outside of the range of the past 800 years. Decreasing monsoon rainfall over the past century is related to increasing sea surface temperature in the Indian Ocean. Spectral analyses of the record are dominated by cycles that are similar to those observed in records of solar activity on centurial timescales. Decadal to interannual cycles in the record appear to originate in the tropical Pacific Ocean. INDEX TERMS: 3344 Meteorology and Atmospheric Dynamics: Paleoclimatology; 3354 Meteorology and Atmospheric Dynamics: Precipitation (1854); 1620 Global Change: Climate dynamics (3309); 1699 Global Change: General or miscellaneous; KEYWORDS: Monsoon, paleoclimate, rainfall, Indian Ocean, speleothem, oxygen isotopes

Citation: Burns, S. J., D. Fleitmann, M. Mudelsee, U. Neff, A. Matter, and A. Mangini, A 780-year annually resolved record of Indian Ocean monsoon precipitation from a speleothem from south Oman, J. Geophys. Res., 107(D20), 4434, doi:10.1029/2001JD001281, 2002 .

\section{Introduction}

[2] The climate of the regions surrounding the Indian Ocean in the Northern Hemisphere is dominated by the seasonally reversing monsoon winds. Studies of recent summer monsoon variation suggest relationships to snow cover in the Himalayas, tropical sea surface temperatures, and teleconnection to El Niño-Southern Oscillation (ENSO) [Webster et al., 1998]. Yet, instrumental records of rainfall in the areas surrounding the Indian Ocean are limited to about 100 years [Sontakke et al., 1993], too short to accurately detect oscillations in rainfall of greater than a few decades. In contrast, most longer records of monsoon variation, derived from marine sediments in the Indian Ocean, lack the resolution to detect changes on timescales of less than several hundred years. Consequently, comparing variations in the monsoon with variation in possible forcing mechanisms is difficult, and how the monsoon

\footnotetext{
${ }^{1}$ Department of Geosciences, University of Massachusetts, Morrill Science Center, Amherst, Massachusetts, USA.

${ }^{2}$ Geological Institute, University of Bern, Bern, Switzerland.

${ }^{3}$ Institute of Meteorology, University of Leipzig, Leipzig, Germany.

${ }^{4}$ Heidelberg Academy of Sciences, Heidelberg, Germany.

varies cyclically on decadal to centurial timescales remains largely unknown. Because success in predicting the future course of Indian Ocean monsoon rainfall is to a large degree dependent on understanding how the monsoon has responded to possible forcing mechanisms in the past, development of a geologic proxy for rainfall in this region would be of great significance.

[3] One possible recorder of changes in monsoon intensity is speleothems. Speleothems, such as stalagmites, stalactites and flowstones, are formed when calcium carbonate precipitates from degassing solutions seeping into limestone caves. That speleothems contain a paleoclimate signal has been recognized for almost 30 years [Hendy and Wilson, 1968]. Paleoclimate information can be gained from such deposits in several ways, including oxygen and carbon isotope ratios of speleothem carbonate [e.g., Bar-Matthews et al., 1997; Dorale et al., 1998]. Also, in near surface caves in areas with a strong annual climate cycle, variations in the thickness of growth layers can be related to climate [Baker et al., 1993].

[4] Previous work in southern Arabia, demonstrates that stalagmite $\delta^{18} \mathrm{O}$ values are inversely related to the amount of rainfall, primarily via an 'amount effect' [Burns et al., 1998, 2001; Neff et al., 2001]. Correlations between oxygen isotope ratios of rainfall and the amount of precipitation typify the strongly convection rainfall systems in tropical 


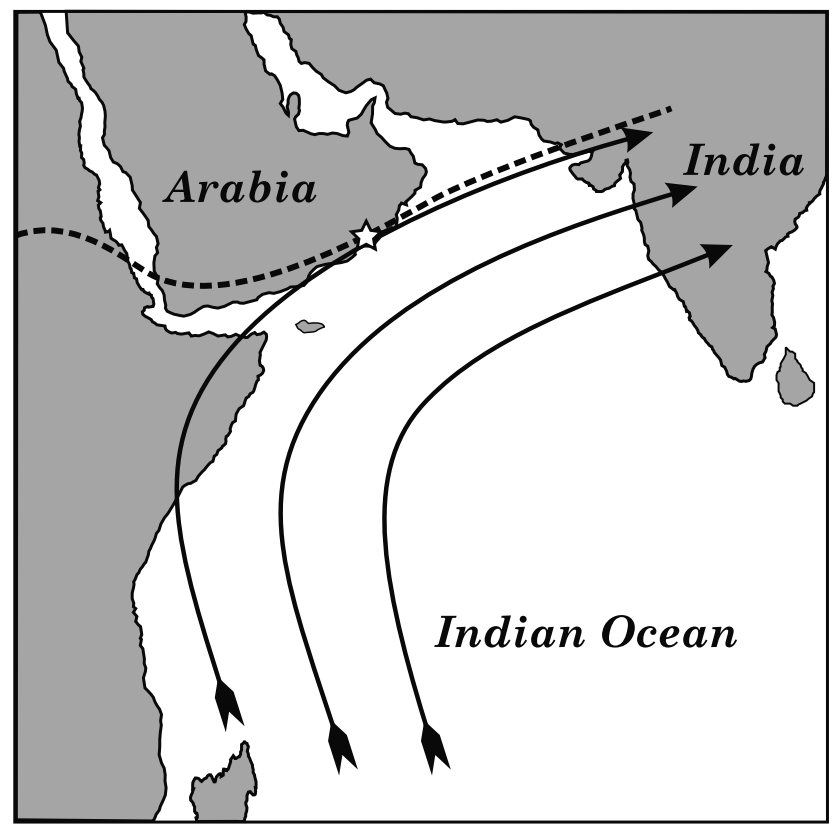

Figure 1. Map of the northwest Indian Ocean region. Arrows show the surface wind pattern during the summer monsoon period, and the dashed line is the location of the ITCZ. Star marks the study site.

regions (e.g. Rozanski). The principle behind the correlation may be thought of as a vertical, temperature-driven, Rayleigh fractionation process: the more intense vertical convection is the greater the fraction of water vapour lost to precipitation and the lower the $\delta^{18} \mathrm{O}$ values of precipitation. Using this principle, we present a 780 year record of monsoon intensity from an annually-laminated stalagmite from the Salalah area of southern Oman. In addition to oxygen isotopes, the record is based on variations in annual growth layer thickness and carbon stable isotope ratios of stalagmite calcite, which are related to the amount of precipitation.

\section{Material and Methods}

[5] Stalagmite S3 was collected from a small, near-surface cave in the Salalah region of southern Oman (Figure 1). The cave consists of two small chambers connected by a $<1$ $\mathrm{m}$ high passageway. The interior chamber, from which the sample was taken, is approximately $10 \mathrm{~m} \times 10 \mathrm{~m}$ with about a $3 \mathrm{~m}$ high ceiling. The cave is poorly ventilated, and measured relative humidity was near $100 \%$ on each of the several occasions the cave was visited [Fleitmann, 2001]. Approximately $20 \mathrm{~m}$ of limestone bedrock with a thin soil cover overlies the cave, so that the flowpath of water from the ground surface to the cave is quite short. The flora on the hillside above the cave is a mixture of trees and shrubs that use the $\mathrm{C} 3$ photsynthetic pathway.

[6] The modern climate of the area is subject to highly seasonal variation in rainfall, controlled by the changing monsoon wind pattern of the Indian Ocean. Annual rainfall averages from $150 \mathrm{~mm}$ at lower altitude to $500 \mathrm{~mm}$ higher in the Dhofar Mountains. In most years, more than $75 \%$ of total annual precipitation falls during the summer monsoon months of June, July and August (Ministry of Water Resources, Sultanate of Oman, unpublished data, 1978-1994). Precipitation occurs not as the heavy rains normally associated with the monsoon, but as fine mist and rain and occult precipitation sourced by fog. S3 was actively growing at the time of sampling, in November 1996.

[7] The sample was cut into halves and polished. The stalagmite consists of white, crystalline calcite throughout. No evidence of a growth hiatus, such as clay bands, etched irregular surfaces, or truncated laminations is present. The slabbed section revealed very regular, sub-millimeter, growth laminations (Figure 2). Over the total length of the $27 \mathrm{~cm}, 780$ layers were counted using digitized photomicrographs. Multiple counts indicate an error of \pm 5 laminae at the bottom of the sample. At the same time, the thickness of each lamination was measured. The average thickness is $0.34 \mathrm{~mm}$.

[8] For oxygen and carbon stable isotope ratio determinations, a total of 603 samples were taken using a hand-held dental drill with an $0.4 \mathrm{~mm}$ drill bit. Samples were taken at approximately $0.4 \mathrm{~mm}$ interval. About $0.5-1 \mathrm{mg}$ of powder was drilled for each sample and analyzed with an on-line, automated, carbonate preparation system linked to a VG Prism II ratio mass spectrometer. Results are shown as the per mil difference between sample and the VPDB standard in delta notation, where $\delta=\left(\mathrm{R}_{\text {sample }} / \mathrm{R}_{\text {standard }}-1\right) \times 1000$, and $\mathrm{R}$ is the ratio of the minor to major isotope. Reproducibility of standard materials is $0.08 \%$ for $\delta^{18} \mathrm{O}$ and better than $0.04 \%$ for $\delta^{13} \mathrm{C}$.

[9] The depositional ages of two samples were determined by measuring the $\mathrm{U} / \mathrm{Th}$ ratios of the samples by thermal ionization mass spectrometry (Table 1). The samples were

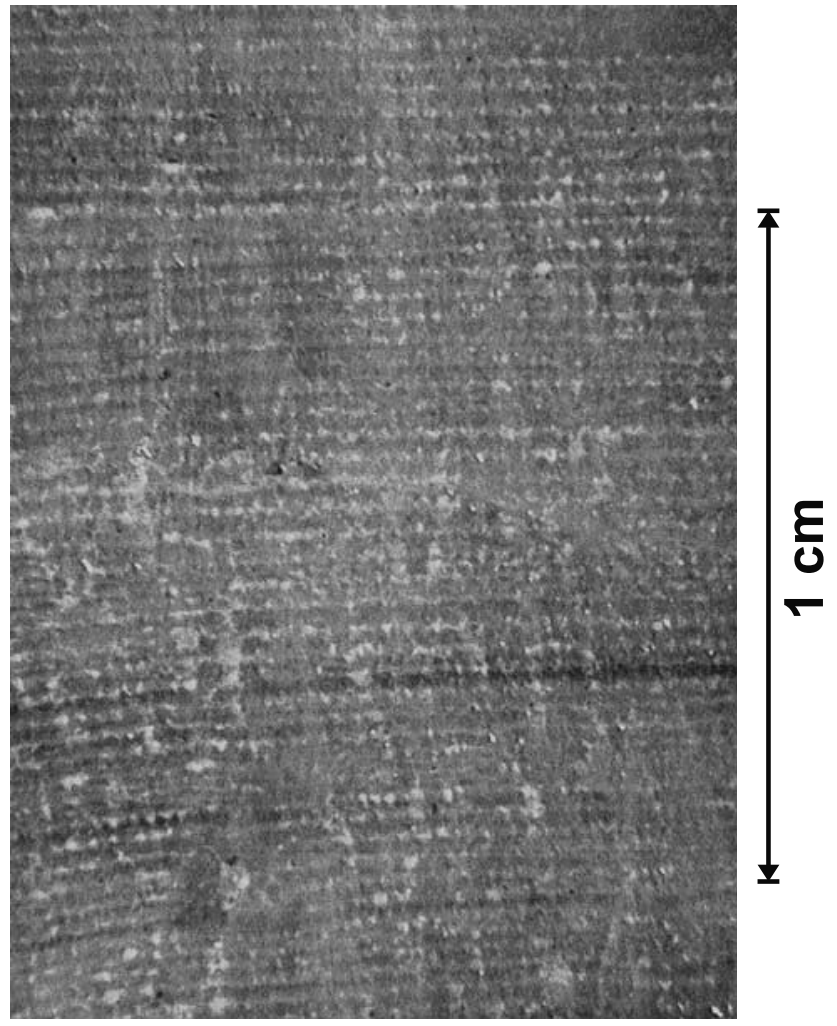

Figure 2. Plain light photomicrograph of a thin section of stalagmite S3 showing very regular laminations. 
Table 1. Stalagmite S3 Uranium and Thorium Isotope Concentrations and Calculated Ages

\begin{tabular}{|c|c|c|c|c|c|c|c|c|c|c|c|c|c|c|}
\hline \multirow[t]{2}{*}{ Depth, nm } & \multicolumn{2}{|c|}{ [Th-320] } & \multicolumn{2}{|c|}{ [Th-232] } & \multicolumn{2}{|c|}{ [U-234] } & \multicolumn{2}{|c|}{ [U-238] } & \multicolumn{2}{|c|}{ dU-234 } & \multicolumn{2}{|c|}{ Age } & \multicolumn{2}{|c|}{ Age (Corrected) } \\
\hline & $\mathrm{pg} / \mathrm{g}$ & $+1-$ & $\mathrm{ng} / \mathrm{g}$ & $+/-$ & $\mathrm{ng} / \mathrm{g}$ & $+1-$ & $\mathrm{mg} / \mathrm{g}$ & $+1-$ & per mil & $+1-$ & $\mathrm{a}$ & $+/-$ & $\mathrm{a}$ & $+1-$ \\
\hline 14 & 020 & 0.003 & 0.414 & 0005 & 0,016 & 0 & 0.279 & 0 & 4 & 3.9 & 460 & 6 & 420 & 55 \\
\hline 245 & 0.029 & 0.001 & 0.318 & 0.003 & 0.014 & 0.0001 & 0.243 & 0.0006 & 40.9 & 4.7 & 780 & 25 & 740 & 24 \\
\hline
\end{tabular}

weighed and dissolved in $7 \mathrm{~N} \mathrm{HNO3.} \mathrm{After} \mathrm{dissolution,} \mathrm{a}$ ${ }^{229} \mathrm{Th}$ spike and ${ }^{233} \mathrm{U} /{ }^{236} \mathrm{U}$ double spike was added for determination of concentration. Isotopic measurements were performed on a Finnigan MAT 262 thermal mass spectrometer equipped with a retarding potential quadrupole system (RPQ). Uranium was determined with a single electron multiplier $\left({ }^{233} \mathrm{U},{ }^{234} \mathrm{U},{ }^{235} \mathrm{U}\right.$ and $\left.{ }^{236} \mathrm{U}\right)$ and one Faraday cup $\left({ }^{238} \mathrm{U}\right)$. The natural ratio of ${ }^{235} \mathrm{U} /{ }^{238} \mathrm{U}$ was used to calibrate the yield of the multiplier. The peak flatness is less than $0.2 \%$ (over $150 \mathrm{ppm}$ in mass). The concentration of the ${ }^{233} \mathrm{U} /{ }^{236} \mathrm{U}$ double spike was calibrated against the NIST CRM 960 uranium standard material. The ${ }^{234} \mathrm{U}$ of this standard was measured at $-31.8 \forall 4.1 \%$ in good agreement with other workers. The reproducibility of the isotope ratio of ${ }^{234} \mathrm{U} /{ }^{238} \mathrm{U}$ during the period of the measurement was at $0.3 \%$. The peak flatness of the RPQ used for determination of ${ }^{230} \mathrm{Th}$ was less than $0.2 \%$ (over $150 \mathrm{ppm}$ in mass). We used a ${ }^{229} \mathrm{Th}$ spike calibrated against an internal ${ }^{230} \mathrm{Th} /{ }^{232} \mathrm{Th}$ standard (HDAKT-1). The reproducibility of the concentration of ${ }^{232} \mathrm{Th}$ was $0.8 \% .{ }^{238} \mathrm{U}$ and ${ }^{232} \mathrm{Th}$ blanks were routinely measured and taken into account.

\section{Results and Discussion}

\subsection{Paleoclimatology of Stalagmite S3}

[10] The very regular laminations revealed in the polished slab of S3 (Figure 2) together with the seasonally varying precipitation pattern, strongly suggest that the laminae are annual. The chronology constructed using the growth layer thickness measurements was verified using the two Th/U age determinations. Measurements at $150 \mathrm{~mm}$ and $245 \mathrm{~mm}$, yield ages of $420 \pm 55$ and $740 \pm 24$ years, respectively. These values fall almost precisely on the age versus depth graph (Figure 3) determined by layer counting. The age versus depth graph shows that stalagmite S3 grew at a quite constant rate beginning at $1215 \pm 5$ A.D. An age for each stable isotope samples was assigned using the age-depth plot derived from the annual growth layer thicknesses. The average sampling interval for the stable isotope analyses is 1.3 years (Figure 4 ).

[11] We derive paleoclimate information from S3 using three essentially independent parameters: annual layer thickness and oxygen and carbon stable isotope ratios of speleothem carbonate. The annual laminations vary from 0.1 to $0.8 \mathrm{~mm}$ in thickness, with an average of $0.35 \mathrm{~mm}$ (Figure 3 ). The $\delta^{18} \mathrm{O}$ values of stalagmite $\mathrm{S} 3$ mostly fall in the range of $0 \%$ to $-1 \%$ (VPDB). These values are about 0.5 per mil enriched in ${ }^{18} \mathrm{O}$ with respect to values expected for isotopic equilibrium with cave drip waters $(+1$ to $-1 \%$ versus $\mathrm{MOW})$ and cave temperatures $\left(26^{\circ} \mathrm{C}\right)$. The $\delta^{13} \mathrm{C}$ values of carbonate from $\mathrm{S} 3$ range from -8 to $-11 \%$. Measurements of the isotopic composition of monsoon rainfall in the region of the cave show that drip waters and rainwaters are isotopically indistinguishable [Fleitmann, 2001].
[12] Time series of all three parameters are plotted in Figure 3. Our interpretation is that all three of these factors vary primarily in response to changes in the amount of precipitation, although controlled by different mechanisms. Variations in laminae thickness reflect changes in annual delivery of dissolved calcium and carbonate to the stalagmite and should be positively correlated to the amount of drip water [Baker et al., 1998]. Cave Defore is very near surface cave, with only about $20 \mathrm{~m}$ of limestone bedrock above the cave. That annual laminations are present is evidence that drip water flow very quickly responds to seasonal changes in rainfall. On annual timescales, increases in monsoon precipitation amount result in a thicker annual layer being deposited.

[13] Changes in the oxygen isotope ratios of the stalagmite calcite primarily reflect changes in the $\delta^{18} \mathrm{O}$ value of drip water which varies over time mainly as a result of changes in $\delta^{18} \mathrm{O}$ of precipitation. The direct effects of temperature on the isotopic records, through the temperature dependence of the water-calcite oxygen isotope fractionation factor, are likely to have been minimal. The range of

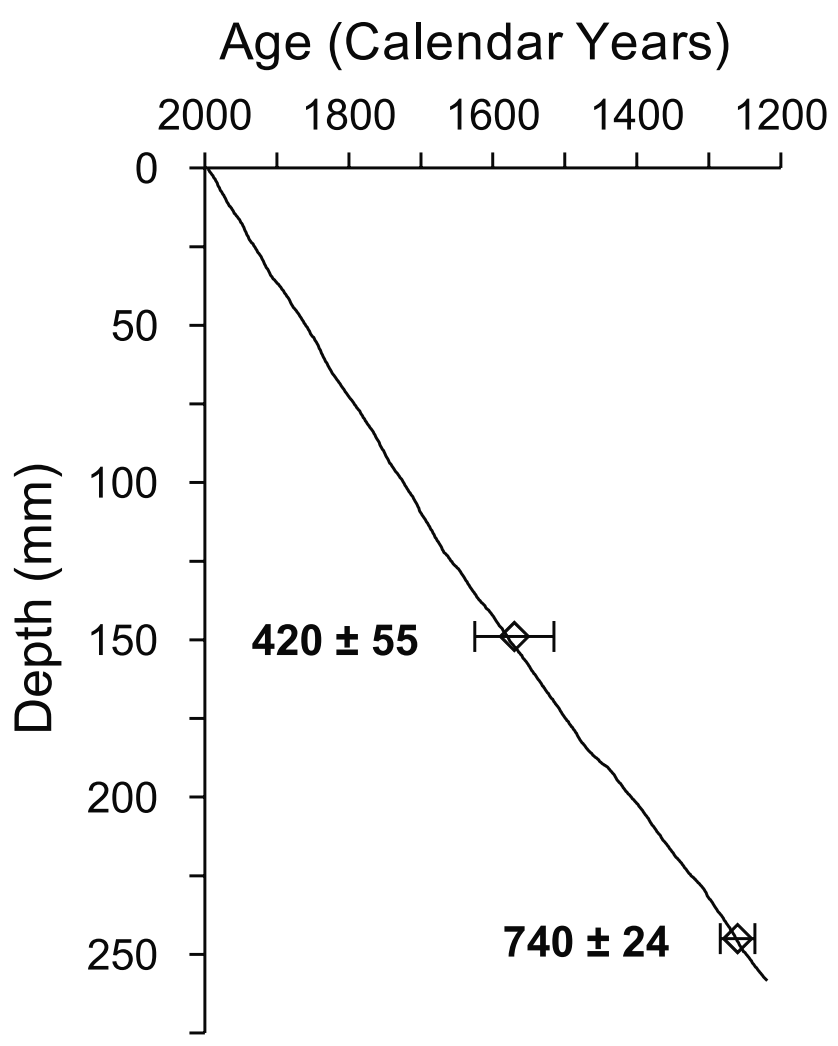

Figure 3. Age versus depth plot for speleothem S3 as determined by layer counting. Also shown are two U/Th age determinations with error bars. The two timescales agree within the error of the U/Th ages. 


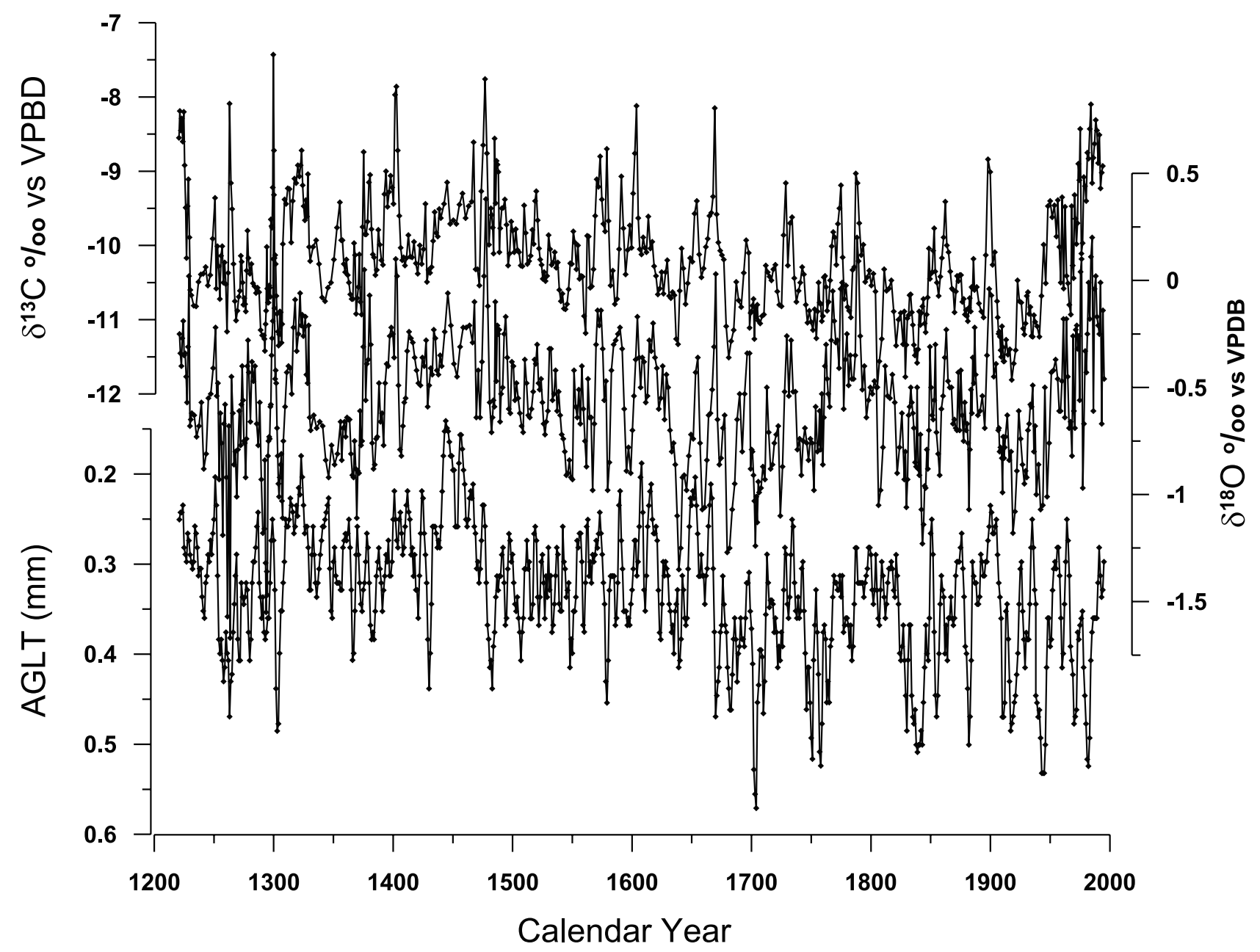

Figure 4. (bottom) Layer thickness, (middle) $\delta^{18} \mathrm{O}$, and (top) $\delta^{13} \mathrm{C}$ of speleothem $\mathrm{S} 3$ versus calender year. See color version of this figure at back of this issue.

observed $\delta^{18} \mathrm{O}$ values $\left(1.2 \%\right.$ ) would require more than $5^{\circ} \mathrm{C}$ of variation in average annual temperature, too large to be reasonable. Nor is the isotopic composition of rainfall related to temperature in low-latitudes [Rozanski et al., 1993]. More likely is that the stalagmite $\delta^{18} \mathrm{O}$ values are inversely related to the amount of rainfall, primarily via an amount effect [Rozanski et al., 1993]. A number of additional processes might also contribute to variation in the $\delta^{18} \mathrm{O}$ signal, for example changes in evaporation in the soil zone, humidity within the cave itself, groundwater infiltration rate or kinetic fractionation [Hendy, 1971] associated with changes in the drip rate. However, all of these processes affect the oxygen isotopic ratios of speleothem calcite in the same "direction" as an amount effect: wetter conditions result in more negative isotopic ratios. Thus, while we cannot with certainty establish the exact degree to which individual factors influence the $\delta^{18} \mathrm{O}$ values of $\mathrm{S} 3$ carbonate, for all processes wetter conditions produce more negative $\delta^{18} \mathrm{O}$ values.

[14] The carbon isotope ratios of speleothem carbonate are also often sensitive indicators of climate [e.g., Frumkin et al., 2000]. In the case of stalagmite $\mathrm{S} 3$, the overall $\delta^{13} \mathrm{C}$ values are determined by the photosynthetic pathway of the plant community in the recharge area and the degree of rock water interaction. The quite negative $\delta^{13} \mathrm{C}$ values, from $-8 \%$ to $-11 \%$, reflect the regional $\mathrm{C} 3$ plant community and short groundwater flowpath between the soil zone and the cave. As is the case for $\delta^{18} \mathrm{O}$, a number of different factors related to rainfall amount play a role in causing the observed variation in $\delta^{13} \mathrm{C}$. These include: changes in the amount of ${ }^{12} \mathrm{C}$ depleted, plant-respired $\mathrm{CO}_{2}$ input to the groundwater in the soil zone as a response to rainfall induced changes in plant activity; more/less interaction with bedrock limestone as the result of less/more rapid flow; or varying kinetic isotope effects related to changing drip rates. As is the case for $\delta^{18} \mathrm{O}$ values, all of these processes affect $\delta^{13} \mathrm{C}$ in the same "direction" with regard to increasing rainfall: more rainfall results in lower carbonate $\delta^{13} \mathrm{C}$ values.

[15] Figure 3 shows that all three measured parameters vary in concert and in a consistent manner with regard to changing precipitation. Thicker growth layers are associated with more negative $\delta^{18} \mathrm{O}$ and $\delta^{13} \mathrm{C}$ values. The linear correlation coefficient $\left(\mathrm{r}^{2}\right)$ between growth layer thickness and $\delta^{18} \mathrm{O}$ is 0.57 , and that between the two isotopes is 0.62 . That all three measured parameters vary together in the sense expected suggests that stalagmite $\mathrm{S} 3$ is an accurate recorder of changes in the amount of precipitation. As a further test of the relationships between rainfall amount and 

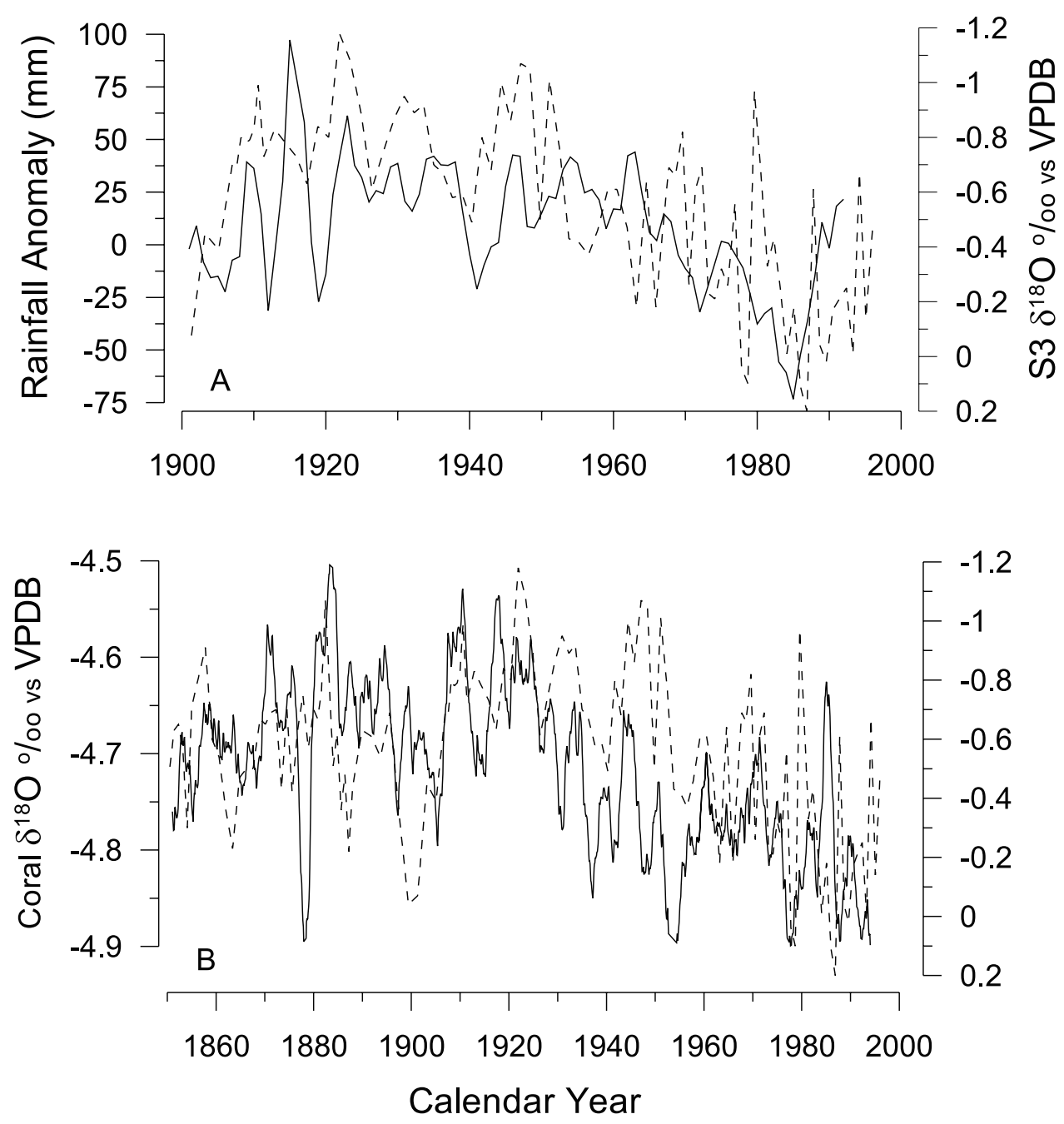

Figure 5. Comparison of $\mathrm{S} 3 \delta^{18} \mathrm{O}$ (orange line) with (a) 3-point running average of historical rainfall data from East Africa and southern Arabia [Vose et al., 1992] for the period from 1900-1990, and (b) 25point running average of coral $\delta^{18} \mathrm{O}$ values from the Seychelles Islands [Charles et al., 1997]. See color version of this figure at back of this issue.

stable isotopes, we sought to calibrate measured rainfall amount and isotopic values of speleothem carbonate. For southern Oman, such a calibration is greatly hindered by the lack of any long, continuous meteorologic record of rainfall. Therefore, we compared the S3 speleothem isotopic record with a time series of gridded annual precipitation anomalies from the Global Historical Climatology Network [Vose et al., 1992] over a broader area from $10^{\circ}$ to $20^{\circ} \mathrm{N}$ and $30^{\circ}$ to $55^{\circ} \mathrm{E}$, essentially the eastern Sahel region of Africa, Yemen and western Oman (Figure 4a). Similar overall patterns for rainfall anomalies and $\delta^{18} \mathrm{O}$ are observed. Individual anomalies in the two records are not always correlated, yet the trend of increasing $\delta^{18} \mathrm{O}$ and decreasing rainfall from the period 1920-1930 through about 1980 can be observed in both records. Other compilations of meteorological records from the Sahel region of Africa also show a trend of decreasing rainfall over this period [Folland et al., 1986].

[16] We also compared our speleothem $\delta^{18} \mathrm{O}$ record to a smoothed (to remove the large annual variation) coral $\delta^{18} \mathrm{O}$ record from near the Seychelles Islands in the central Indian Ocean [Charles et al., 1997]. The coral record is primarily a function of sea surface temperature (SST) variation related to changes in the intensity of monsoon wind-driven upwelling [Charles et al., 1997]. Despite possible differences in age models of several $1-3$ years, the coral and speleothem $\delta^{18} \mathrm{O}$ curves are remarkably similar (Figure 4b). They also show the expected interrelationship, with more negative coral values (warmer SST and weaker monsoon wind) associated with less negative speleothem values (less precipitation). Based on the comparisons between the speleothem and regional rainfall and coral records, we conclude that speleothem S3 is an accurate recorder of monsoonrelated changes in precipitation over a broad region.

\subsection{Long-Term Trends in S3 Data Set}

[17] The 780 yearlong time series (Figure 3) show no significant long-term trend in any of the three rainfall proxies. Nor are values from the post-industrial period or 20th century anomalous compared to those from the preindustrial period. In contrast, high-resolution data covering approximately the same time period from Himalayan ice cores show a marked increase in $\delta^{18} \mathrm{O}$ values in the late 20th 

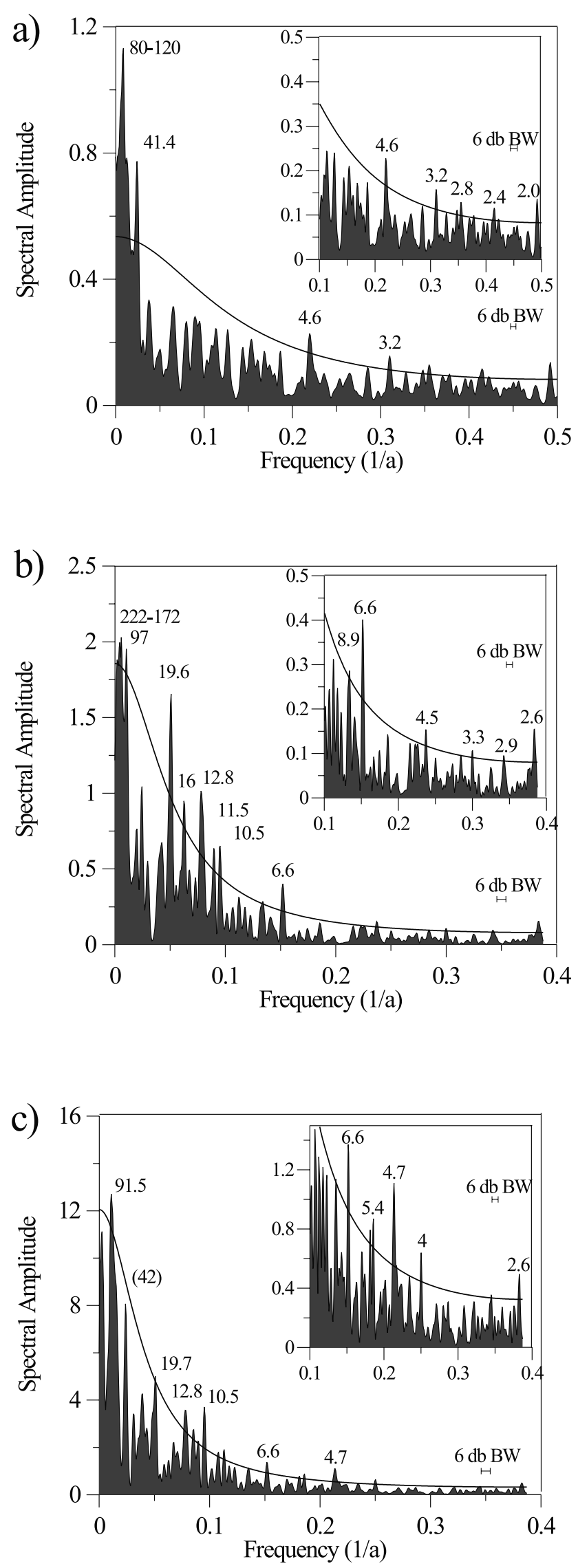

century compared to the previous $\sim 400$ years [Thompson et al., 2000]. Accumulation rate in the ice cores decreases from the 19th to 20th centuries [Thompson et al., 2000]. Both changes are thought to reflect the global warming trend of the twentieth century [Mann et al., 1998]. It might be expected that monsoon rainfall would increase in response to increased temperatures and decreased snow cover in the Himalayas, which are thought to control the timing of the onset and intensity of monsoon rainfall in the following summer [Dickson, 1984; Meehl, 1994a]. Yet, our record suggests that such an increase did not occur. Over most of the twentieth century monsoon rainfall was decreasing. The explanation may be that monsoon intensity responds to the difference in temperature between the Indian Ocean and the Tibetan Plateau [Meehl, 1994b], rather than solely to conditions within the latter. Warming of the Indian Ocean during the 20th century may have decreased the land-sea thermal gradient and reduced monsoon intensity [Meehl, 1994b]. The correspondence between Indian Ocean mean annual sea surface temperatures (the Seychelles coral $\delta^{18} \mathrm{O}$ record [Charles et al., 1997]) and precipitation (S3 $\left.\delta^{18} \mathrm{O}\right)$ supports this hypothesis.

\subsection{Spectral Analyses}

[18] Spectral analyses of layer thickness, $\delta^{18} \mathrm{O}$ and $\delta^{13} \mathrm{C}$ were done using the Spektrum program for unevenly sampled data sets [Schulz and Stattegger, 1997]. All three records contain cyclical components (Figure 5). As is the case for speleothem records of monsoon variation during the early Holocene [Neff et al., 2001], most of the identified cycles are close to those observed in various records of solar activity [Sonnett et al., 1992]. The $\sim 200$ year cycle in $\delta^{18} \mathrm{O}$, which is present in the $\delta^{13} \mathrm{C}$ but does not exceed the $90 \%$ confidence limit, is close to the 206 year cycle in solar activity. Similarly, the $80-120$ year cycle in layer thickness, 97 year cycle in $\delta^{18} \mathrm{O}$ and 91 year cycle in $\delta^{13} \mathrm{C}$ are within error of the 90 year Gleisberg cycle observed in records of sunspot activity. These two cycles are also present in the $\Delta^{14} \mathrm{C}$ record of tree rings, in which they are attributed to solar forcing [Stuiver and Braziunas, 1993].

[19] Cycles of around 20 year and 12 year in duration are present in both isotopic records. These cycles are similar in length to the 20-23 year Hale cycle in magnetic solar activity and to the 11 year sunspot cycle, respectively. However, the total change in solar irradiance over the 11 year solar cycle is around $0.1 \%$, and perhaps 0.2 to $0.3 \%$ on centennial timescales, with somewhat greater variability at

Figure 6. (opposite) Spectral analyses of (top) layer thickness, (middle) $\delta^{18} \mathrm{O}$, and (bottom) $\delta^{13} \mathrm{C}$ data sets. Also shown are red noise curves for each data set. Spectral peaks which rise above the red noise line are statistically significant at the $90 \%$ confidence level. The layer thickness record has statistically significant (at the $90 \%$ confidence level) cycles at $\sim 101,41,4.6$ year and a cluster of cycles between 3.2 and 2.0 year. The $\delta^{18} \mathrm{O}$ records has significant cycles at $\sim 204,97,19.8,16.1,12.8,6.6$ year, and several cycles of 4.5 year to 2.6 year in length. The $\delta^{13} \mathrm{C}$ record shows a very similar pattern to $\delta^{18} \mathrm{O}$, except that the $\sim 200$ year and 16 year cycles are not present, and the $\sim 20$ year cycle falls below the $90 \%$ confidence level. 

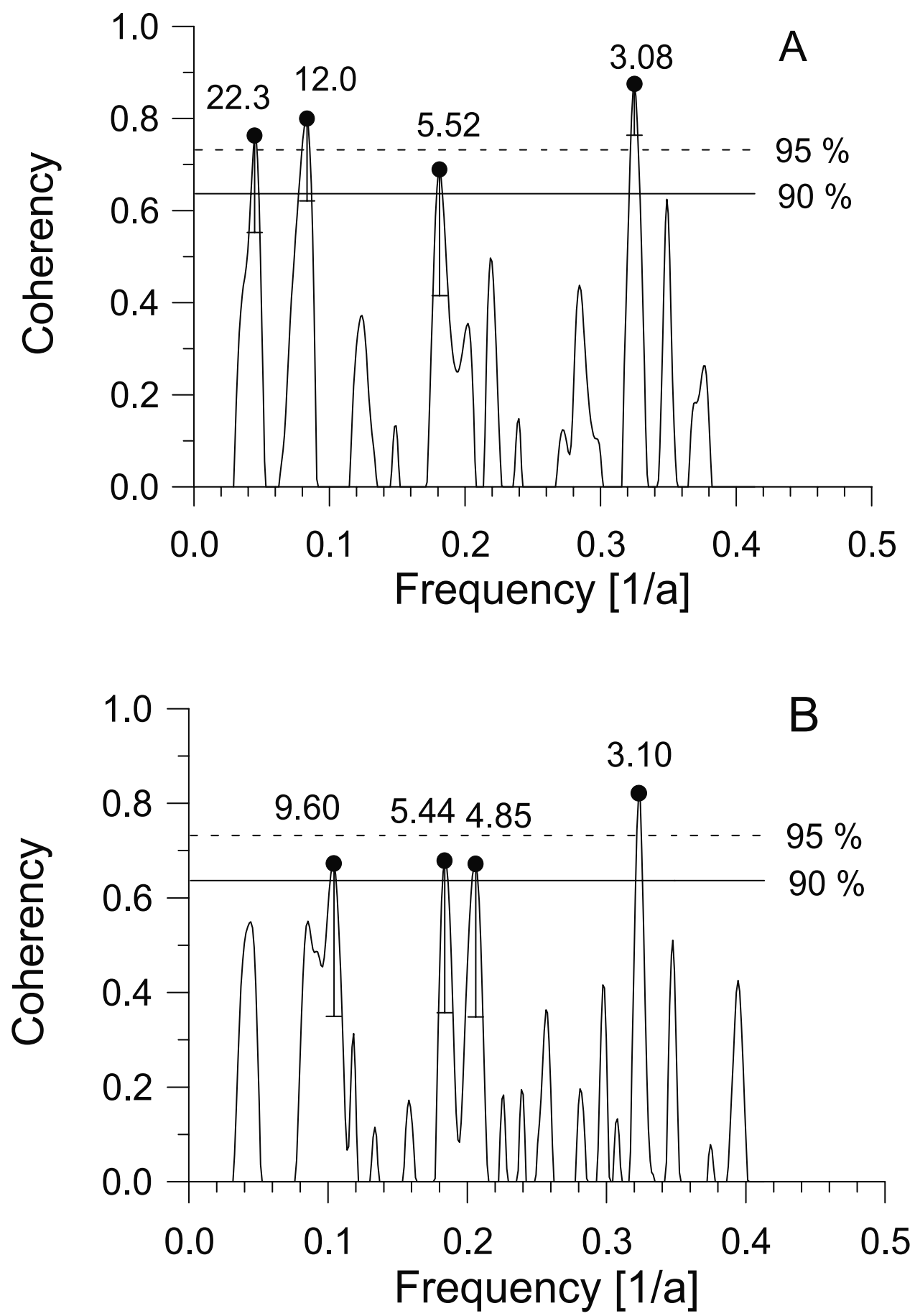

Figure 7. Cross-spectral analysis of the $\mathrm{S} 3$ and (a) Seychelles coral $\delta^{18} \mathrm{O}$ [Charles et al., 1997] and (b) the NINO3.4 sea surface temperature records. Strong coherency between S3 and the coral is observed for decadal ( $\sim 20$ and $\sim 12$ year) and interannual ( $\sim 5$ and $\sim 3$ year) cycles. Coherency between S3 and the Nino3.4 data is strongest at the $\sim 3$ year cycle.

higher wavelengths [Fligge and Solanki, 2000]. Any direct effect of changing solar irradiance on the monsoon, such as through increased or decreased sensible heating of the Tibetan Plateau is very unlikely. Nor do comparisons of solar forcing with the S3 records show any direct link between the two.

[20] Alternatively, the decadal scale cycles in monsoon rainfall recorded by S3 may be related to decadal variability in other parts of the climate system. The monsoon has been shown to strongly interact with both the El Nino- Southern Oscillation (ENSO) [Webster et al., 1998; Charles et al., 1997; Cole et al., 2000], and decadal-scale variability in the tropical Pacific. In particular, coral records of Indian Ocean SST's are coherent with tropical Pacific climate at interannual to decadal periods [Charles et al., 1997; Cole et al., 2000]. A number of cycles with periods of 2-3 years are 


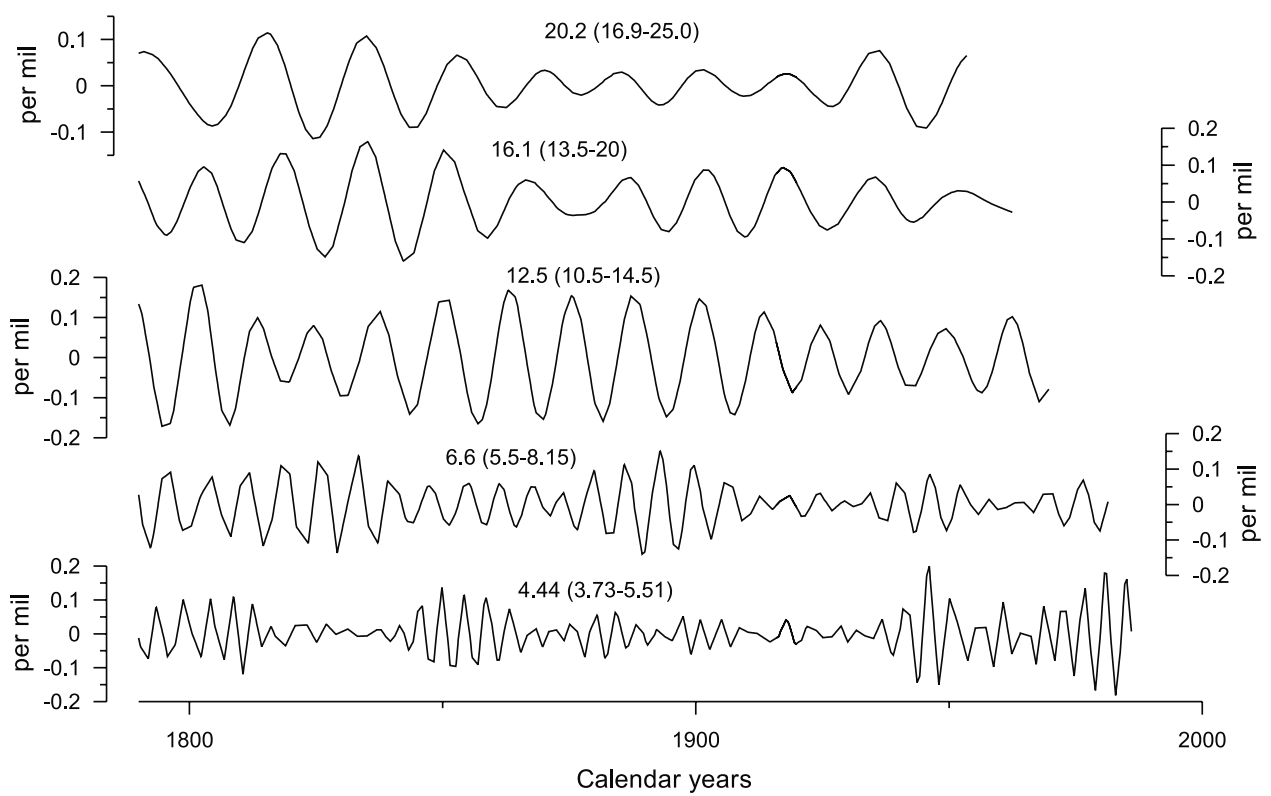

Figure 8. Bandpass filtered spectra of the $\mathrm{S} 3 \delta^{18} \mathrm{O}$ record at frequencies centered on 20, 16.1, 12.5, 6.6, and 4.5 years.

found in both of the speleothem isotopic records, and within the layer thickness record, indicating that ENSO-type variability is present. Cycles of 4.6 year in layer thickness and 6.6 year in both isotopic records, which may be ENSOrelated are also present. El Niño events correlate with anomalous warming in the equatorial Indian Ocean [Chambers et al., 1999] and often with reduced monsoon rainfall [Webster et al., 1998].

[21] Using cross-spectral analysis, we made comparisons between the decadal and interannual periods in the speleothem record, the Seychelles coral $\delta^{18} \mathrm{O}$, and the Niño 3.4 ENSO index [Kaplan et al., 1998]. The highest coherency occurs between the speleothem record and coral data from the Seychelles (Figure 6a), with cycles at $22 \mathrm{y}, 12 \mathrm{y}$, and 3 year all coherent at the $95 \%$ confidence level and at 5.5 year at $90 \%$ confidence level. The NINO3.4 index is also coherent with the $\mathrm{S} 3 \delta^{18} \mathrm{O}$ record in ENSO bandwidths, the 3 year cycles in the records is coherent at $95 \%$ confidence level, and $4.8 \mathrm{y}, 5.4$ year and 9.6 year cycles are coherent at the $90 \%$ confidence level (Figure 6b). The strong coherence between monsoon rainfall $\left(\mathrm{S} 3 \delta^{18} \mathrm{O}\right)$ and Indian Ocean SST (Seychelles coral $\delta^{18} \mathrm{O}$ ), and the further demonstrated coherency between the latter and Pacific climate records [Charles et al., 1997; Cole et al., 2000] suggests that the decadal components of monsoon rainfall variability also have their origin in the tropical Pacific and are related to decadal ENSO variability.

[22] Because of the strong coherency between the S3 $\delta^{18} \mathrm{O}$ and other tropical climate records, and because the S3 record is longer, by at least 400 years, than any existing coral record we can use the S3 data to address the question of what the dominant frequencies of tropical climate variation have been over the past almost 800 years. We made bandpass filtered records for each of the decadal and shorter frequencies in the $\mathrm{S} 3 \delta^{18} \mathrm{O}$ record (Figure 6). Based on a 155 year coral record, Urban et al. [2000] suggested that a change in ENSO behavior from dominance by decadal-scale variability before $\sim 1900$ to shorter periods thereafter. They also noted a shift to a concentration centered at approximately 4 years around 1955 . The $\mathrm{S} 3 \delta^{18} \mathrm{O}$ record shares some of these characteristics, with generally weakening decadal variance over much of the past 150 years, and sharp strengthening of 4 year cyclicity at around 1950 (Figures 7 and 8). Urban et al. [2000] also suggested a relationship between background climate and the frequency of ENSO variance, with cooler global climate periods associated with increased decadal variability. While this pattern may be valid for the late nineteenth and twentieth centuries, the longer term perspective provided by the S3 speleothem record shows no coherent relationship between global temperature estimates of the past six centuries [Mann et al., 1998] and the dominant frequency of monsoon rainfall variation. For example, the periods from 13001350 and $1650-1750$ show strong decadal variance in S3 $\delta^{18} \mathrm{O}$, but neither period is anomalously cool in reconstructed temperature records [Mann et al., 1998].

\section{Conclusions}

[23] The oxygen and carbon isotopic ratios and annual growth layer thicknesses of a stalagmite from the Salalah area of southern Oman provide a record of changes in monsoon rainfall over the past 780 years. The $\delta^{18} \mathrm{O}$ and $\delta^{13} \mathrm{C}$ values of speleothem calcite are inversely related to precipitation, while growth layer thickness is proportional to precipitation. None of the three time series shows a unidirectional trend, nor is the 20th century anomalous in comparison to the previous 700 years. Over most of the twentieth century monsoon rainfall was decreasing in response to warming of the Indian Ocean. Spectral analyses of the three time series demonstrate that on centurial timescales, monsoon variation is primarily related to solar variation. On decadal and shorter timescales, monsoon variation is associated with decadal variation in the tropical 
Pacific and ENSO. No general relationship between the strength of ENSO-scale variation and the background state of global temperatures is observed.

[24] Acknowledgments. We are very grateful to Ali Al Kathiri for showing us the location of Cave Defore and to Zaher Al Suleimani of the Ministry of Water Resources and Hilal bin Mohammed al Azri of the Ministry of Commerce, Sultanate of Oman, for their support and cooperation

\section{References}

Baker, A., P. L. Smart, R. L. Edwards, and D. A. Richards, Annual growth banding in cave stalagmite, Nature, 304, 518-520, 1993.

Baker, A., D. Genty, W. Dreybrodt, W. L. Barnes, N. Y. Mocker, and J. Grapes, Testing theoretically predicted stalagmite growth rate with recent annually laminated samples: Implications for past stalagmite deposition, Geochim. Cosmochim. Acta, 62, 393-402, 1998.

Bar-Matthews, M., A. Ayalon, and A. Kaufman, Late Quaternary paleoclimate in the eastern Mediterranean region from stable isotope analysis of speleothems at Soreq Cave, Israel, Quat. Res., 47, 155-168, 1997.

Burns, S. J., A. Matter, N. Frank, and A. Mangini, Speleothem-based paleoclimate record from northern Oman, Geology, 26, 499-502, 1998.

Burns, S. J., D. Fleitmann, A. Matter, U. Neff, and A. Mangini, Speleothem evidence from Oman for continental pluvial events during interglacial periods, Geology, 29, 623-626, 2001.

Chambers, D. P., B. D. Tapley, and R. H. Stewart, Anomalous warming in the Indian ocean coincident with El Niño, J. Geophys. Res., 104, $3035-$ 3047, 1999.

Charles, C. D., D. E. Hunter, and R. G. Fairbanks, Interaction between the ENSO and the Asian monsoon in a coral record of tropical climate, Science, 277, 925-928, 1997.

Cole, J. E., R. B. Dunbar, T. R. McClanahan, and N. A. Muthiga, Tropical forcing of decadal variability in the western Indian Ocean over the past two centuries, Science, 287, 617-620, 2000.

Dickson, R., Eurasian snow cover versus Indian monsoon rainfall-An extension of the Hahn-Shukla results, J. Clim. Appl. Meteorol., 23 , $171-173,1984$

Dorale, J. A., R. L. Edwards, E. Ito, and L. A. Gonzalez, Climate and vegetation history of the mid-continent from 75 to $25 \mathrm{ka}$ : A speleothem record from Crevice Cave, Missouri, USA, Science, 282, 1871-1874, 1998.

Fleitmann, D., Annual to millennial scale monsoon variability recorded in Holocene and Pleistocene stalagmites from Oman, Ph.D. dissertation, Univ. of Bern, Bern, Switzerland, 2001.

Fligge, M., and S. K. Solanki, The solar spectral irradiance since 1700 , Geophys. Res. Lett., 27, 2157-2160, 2000.

Folland, C. K., T. N. Palmer, and D. E. Parker, Sahel rainfall and worldwide sea temperatures, 1902-85, Nature, 320, 602-604, 1986.

Frumkin, A., D. C. Ford, and H. C. Schwarcz, Paleoclimate and vegetation of the last glacial cycles in Jerusalem from a speleothem record, Global Biogeochem. Cycles, 14, 863-877, 2000.

Hendy, C. H., and A. T. Wilson, Paleoclimate data from speleothems, Nature, 216, 48-51, 1968.

Hendy, C. H., The isotopic geochemistry of speleothems, I, The calculation of the effects of different modes of formation on the isotopic composition of speleothems and their applicability as paleoclimate indicators, Geochim. Cosmochim. Acta, 35, 801-824, 1971.

Kaplan, A., et al., Analyses of global sea surface temperature, 1856-1991, J. Geophys. Res., 103, 18,567-18,589, 1998.

Mann, M. E., R. S. Bradley, and M. K. Hughes, Global scale temperature patterns and climate forcing over the past six centuries, Nature, 392, 779-787, 1998

Meehl, G. A., Influence of the land surface in the Asian summer monsoon, external conditions versus internal feedbacks, J. Clim., 7, 1033-1049, 1994a.

Meehl, G. A., Coupled ocean-atmosphere-land processes and south Asian monsoon variability, Science, 265, 263-267, 1994b.

Neff, U., S. J. Burns, A. Mangini, M. Mudelsee, D. Fleitmann, and A. Matter, Strong coherence between solar variability and the monsoon in Oman between 9 and 6 kyr ago, Nature, 411, 290-293, 2001.

Rozanski, K., L. Araguás-Araguás, and R. Gonfiantini, Isotopic patterns in modern global precipitation, in Climate Change in Continental Isotopic Records, Geophys. Monogr. Ser., vol. 78, edited by P. K. Swart, K. C. Lohmann, J. McKenzie, and S. Savin, pp. 1-36, AGU, Washington, D.C., 1993

Schulz, M., and K. Stattegger, Spectrum: Spectral analysis of unevenly spaced paleoclimatic time series, Comput. Geosci., 23, 929-945, 1997.

Sonnett, C. P., M. S. Gianpapa, and M. S. Matthews (Eds.), The Sun in Time, Univ of Ariz. Press, Tucson, 1992.

Sontakke, N. A., G. B. Plant, and N. Singh, Construction of all-India summer monsoon rainfall series for the period 1844-1991, J. Clim., 6, 1807-1811, 1993.

Stuiver, M., and T. F. Braziunas, Sun, ocean climate and atmospheric ${ }^{14} \mathrm{CO}_{2}$ : An evaluation of causal and spectral relationships, Holocene, 3 , $289-305,1993$

Thompson, L. G., T. Yao, E. Mosley-Thompson, M. E. Davis, K. A. Henderson, and P.-N. Lin, A high-resolution millennial record of the South Asian Monsoon from Himalayan ice cores, Science, 289, 19161919, 2000

Urban, F. E., J. E. Cole, and J. T. Overpeck, Influence of mean climate change on climate variability from a 155-year tropical Pacific coral record, Nature, 407, 989-993, 2000.

Vose, R. S., R. L. Schmoyer, P. M. Steurer, T. C. Peterson, R. Heim, T. R. Karl, and J. Eischeid, The Global Historical Climatology Network: Longterm monthly temperature, precipitation, sea level pressure, and station pressure data, ORNL/CDIAC-53, NDP-041, Carbon Dioxide Inf. Anal. Cent., Oak Ridge Natl. Lab., Oak Ridge, Tenn., 1992.

Webster, P. J., V. O. Magaña, T. N. Palmer, J. Shukla, R. A. Tomas, M. Yanai, and T. Yasunari, Monsoons: Processes, predictability, and the prospects for prediction, J. Geophys. Res., 103, 14,451-14,510, 1998.

S. J. Burns, Department of Geosciences, University of Massachusetts, Morrill Science Center, Amherst, MA 10003, USA. (sburns@geo.umass. edu)

D. Fleitmann and A. Matter, Geological Institute, University of Bern, Baltzerstrasse 1, Bern CH-3012, Switzerland.

M. Mudelsee, Institute of Meteorology, University of Leipzig, Stephanstrasse 3, Leipzig, Germany D-04103.

U. Neff and A. Mangini, Heidelberg Academy of Sciences, Im Neuenheimer Feld 229, Heidelberg, Germany D-69120. 


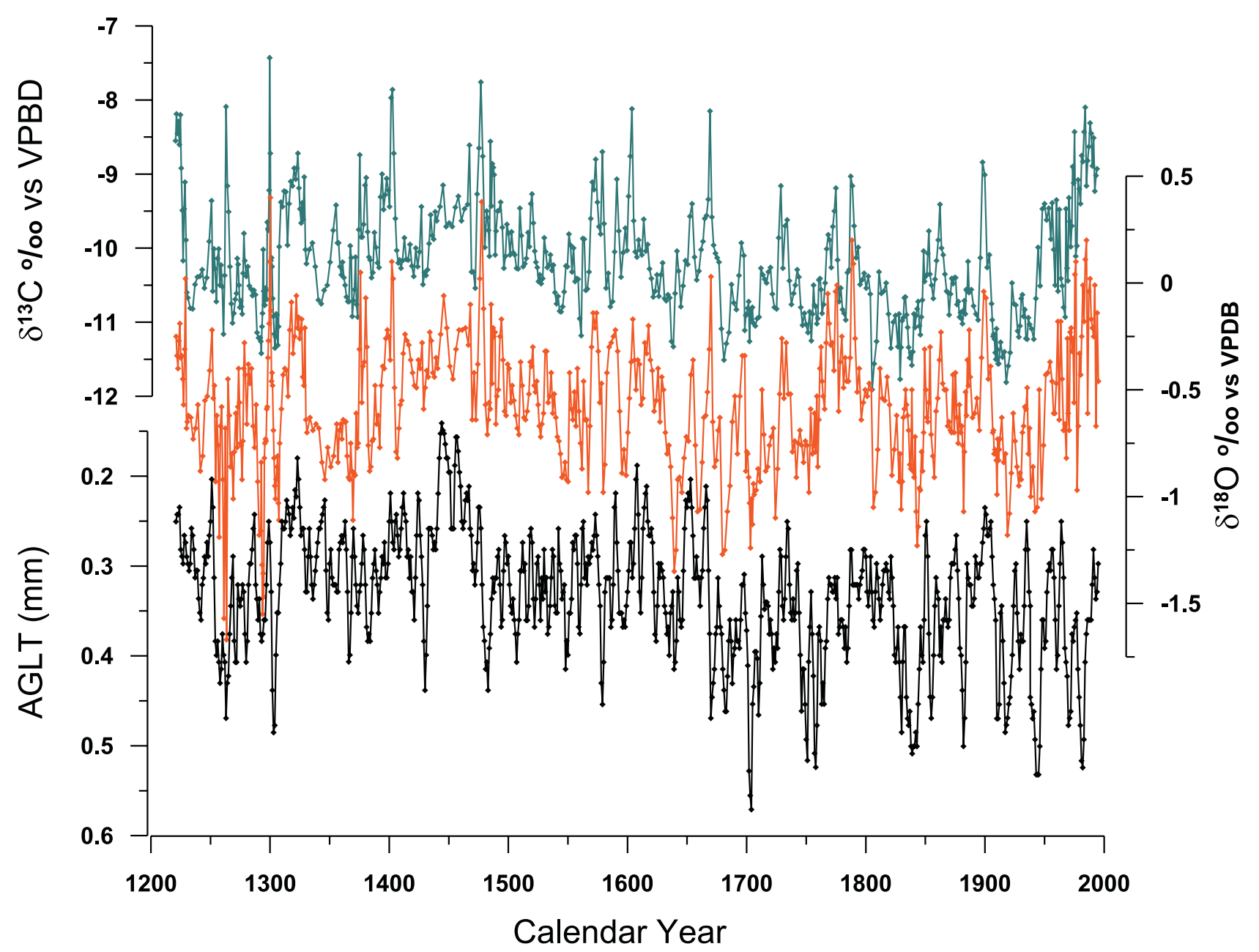

Figure 4. (bottom) Layer thickness, (middle) $\delta^{18} \mathrm{O}$, and (top) $\delta^{13} \mathrm{C}$ of speleothem $\mathrm{S} 3$ versus calender year. 

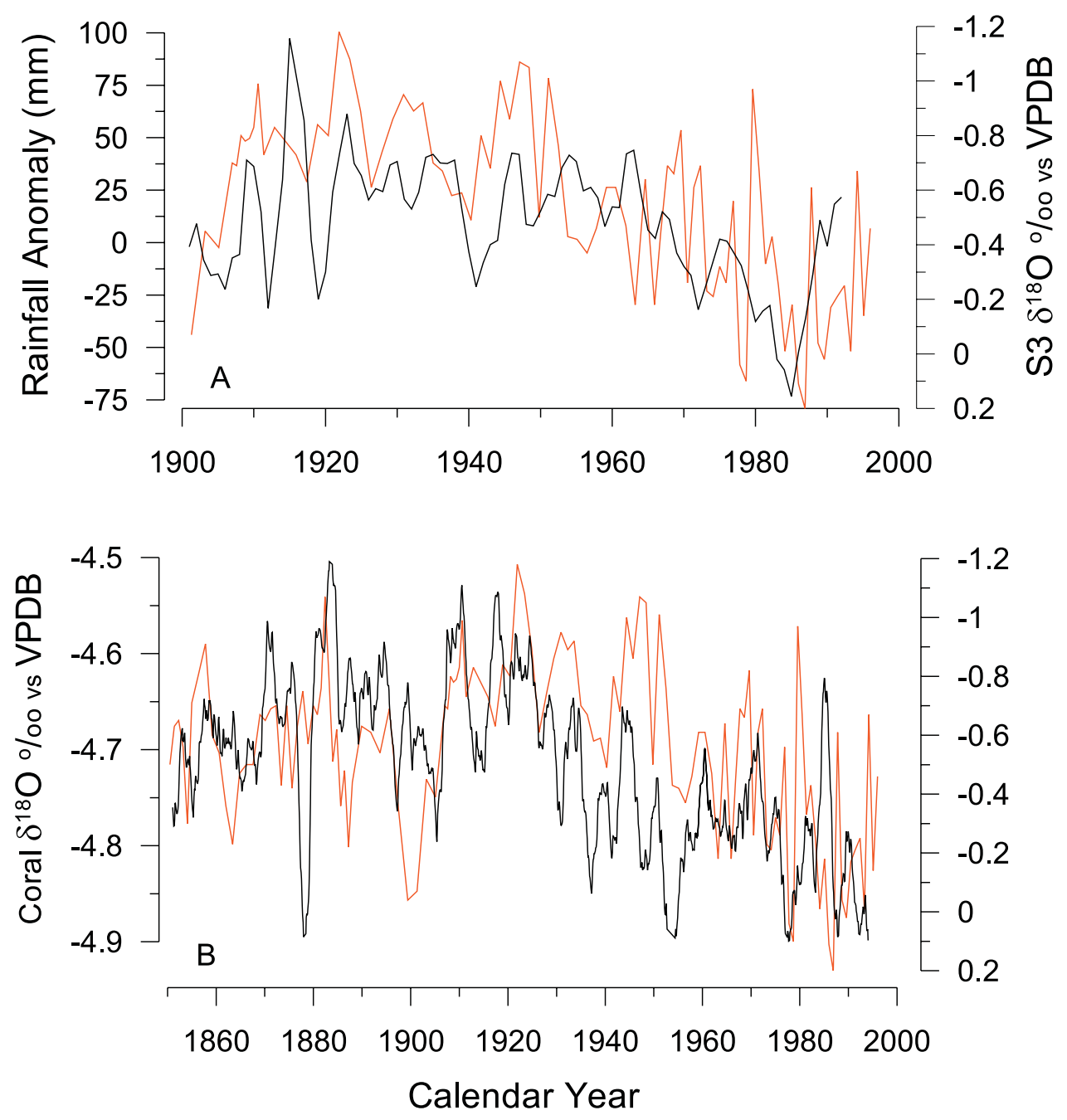

Figure 5. Comparison of $\mathrm{S} 3 \delta^{18} \mathrm{O}$ (orange line) with (a) 3-point running average of historical rainfall data from East Africa and southern Arabia [Vose et al., 1992] for the period from 1900-1990, and (b) 25point running average of coral $\delta^{18} \mathrm{O}$ values from the Seychelles Islands [Charles et al., 1997]. 